\title{
Being Fit In the University: The Culpability of Exams and Self Esteem
}

\author{
Aroyewun B. Afolabi ${ }^{1}$, Adeyemo S. Oladotun ${ }^{2}$, EzemokweChinedu O. ${ }^{2}$, \\ Ariyo O. Joy, Effiong Vera ${ }^{2}$, OyeyemiTolulope $\mathrm{E}^{2}$. \\ ${ }^{1,2}$ (Federal neuropsychiatric Hospital, Uselu, Benin-city, Nigeria)
}

\begin{abstract}
Transiting from home to the university environment could be distressful to some students but some factors are inherent in the school which can be more distressing, coupled with the fact that the number of students from higher institution presenting with symptoms of mental ill health in recent years has increased, the study considered the influence of test anxiety and self-esteem on psychological distress of University students. Undergraduate Students inPsychology on practicum rounds at Federal Neuropsychiatric Hospital, Uselu, Benin City, Edo State, were selected as participants in the study using convenient sampling technique. I47 participants in which female were 84 (57.1.9\%) while male were 63 (42.9\%) and the mean age was 28.54 while SD was 5.124. Test anxiety was measured using Test Anxiety Inventory, (TAI), Self-esteem was assessed through Index of Self-esteem while psychological distress was measured through Symptoms Checklist-90. It was found out that those who score high on self-esteem have less psychological distress than those who score low on self-esteem; while participants with high scores on test anxiety are more psychologically unfit than low scorers on test anxiety. The study is a call for more proactive measures in the area of academic and exam structure of university students that will cause less psychological distress and also call for a supporting school structure that will enhance the monitoring and support of esteem issues of university students.
\end{abstract}

Keywords: Being fit, university, culpability, exam, self-esteem.

\section{Introduction}

According to WHO, ${ }^{1}$ health is a state of complete physical, mental and social well-being and not merely the absence of disease or infirmity. By physical, it means there is a structural soundness in the bones, muscles and organs. Mental suggests a state of well-being enabling people to realize their abilities, cope with normal stresses of life, work productively and fruitfully and make contributions to their communities ${ }^{1}$ while social health relates to the environments of the people. For all individuals across age, gender, educational, occupation, and cultural background, mental health is crucial to determine their overall well-being most especially for university students.

The transition from home to university, the normal adjustment processes of this phase of life, expectations of success, as well as financial, personal and cultural pressures are added to the dynamic milieu of a new environment.Tertiary education is considered a highly stressful period and this stressful environment can effect negatively on the psychological and physical well being of university students, ${ }^{2}$ Previous studies suggest high rates of psychological morbidity among university students worldwide, especially depression and anxiety, ${ }^{3,4,5}$. Also, the number of students from higher education presenting with symptoms of mental ill health in recent years has increased ${ }^{6}$ and the mental health of students in the caring and related professions has been an area of concern ${ }^{7}$.

There is substantial evidence that stress can lead to various negative consequences for individuals, including somatic diseases, mental health disorders or feelings of exhaustion.Studies among first year medical students revealed high prevalence of psychological distress where they are adjusting to the new environment of medical training and the poorest psychological health was reported during examination periods ${ }^{8.9 .10,11}$

With these confirmations however, students' psychological wellness/fitness is worthy of research beam light.With scarce reports on the psychological distress of students, the study will provide a research link along this way and also provide a reference point for both students and researchers alike.This study will also help in the designing and provisioning for an institution based preventive programming efforts as regards exams worry and address a wide variety of concerns from academic to any other factors that could cause psychological distress. 
Psychological problems (which may even mean everyday stresses or experience of negative life events) among student population varies in occurrence.At any given time if one randomly examines the student wellbeing one can find that by every 10 students, one will have emotional conflicts severe enough to merit professional help ${ }^{12}$

Considering gender being a risk factor of more experience of psychological distress ${ }^{13}$ studied among 207 high school students and they found that adolescent girls reported more life events, higher levels of stress due to the life events, and more use of coping strategies than boys. More specifically, girls tend to report significantly more negative life events than boys across all ages of adolescence as well as higher levels of stress. Consistent with this finding ${ }^{14,15}$ reported similar finding that psychological distress is higher among female than male students. This finding is significantly reported by ${ }^{16}$

Another important socio-demographic data on the measure of psychological distress of students is age but it has received a very little attention in research of this nature ${ }^{17}$ although, they found out that psychological distress disaggregated as anxiety and depression, with age 20 years or below were significantly associated with the level of depression alone.

The mental health of students can be upset by exams culture ${ }^{18}$ Although, tests and examinations at all stages of education, especially at higher education level have been considered an important and powerful tool for decision making in our competitive society, with people of all ages being evaluated with respect to their achievement, skills and abilities, yet it has been linked with many psychological disturbances such as anxiety. Exam, most of the times, especially at the undergraduates collegiate courses represent a cross for most students, although assignments, impromptu class works, with other similar exercises are in growing relevance these days, exams still represent the final of all grades.

Test anxiety and anxiety disorders share some characteristics, and students with test anxiety often have anxiety disorders, however, these conditions are different. People with anxiety disorders have trait anxiety, which means that their high levels of stress appear to be on-going personal characteristics that are evident across settings and situations ${ }^{19}$ People with test anxiety, however, seem to have state anxiety, which means that their high levels of stress are situation specific (e.g., extreme and unwarranted tension during testing or evaluative activities $)^{19}$

Test/Exam anxiety typically involves behaviours, feelings, reactions, and thoughts ${ }^{20}$ that occurs at all academic levels. Test anxiety is believed to be learnt in educational settings, typically evoked during the earlier school years ${ }^{21}$. Several factors can potentially affect the development of test anxiety. However, these factors are not all active at the same time during a child's development; an individual's reaction to a specific test situation is shaped by the specific influence of the factors active during and leading up to the test ${ }^{22}$

The first scales for assessing individual differences in test anxiety were developed in the 1950s and typically focused on single primary components. These one-dimensional approaches were replaced by seminal two-component approaches, i.e. worry and emotionality or state and trait, in the $1960-1970 \mathrm{~s}^{23}$ More recent advances have led to the development of more sophisticated and psychometrically-sound measures of test anxiety. The test anxiety construct today is theorized and conceptualized as being complex, multi-dimensional, and dynamic, and represents a key area in contemporary test anxiety research with characteristic factors or subscales that vary depending on the instrument used. The first distinction is between two basic dimensions in the experience of anxiety, emotionality and worry, which are accepted by most contemporary researchers as major components of test anxiety ${ }^{24}$ and are empirically distinct but interrelated ${ }^{25}$. Worry is a cognitive distractor that stems from the individual's valuation of their individual's valuation of their performance.It can be experienced over relatively long periods of time, some-times beginning several days before an exam, and may persist throughout testing.

Emotionality denotes the individual's subjective awareness and understanding physiological reactions in different evaluative situations (i.e. the more physiological part). It is experienced at a specific point in time ${ }^{26}$ and is dependent on the context, and so can potentially be adjusted or modulated by changing the testing environment ${ }^{25}$. Worry has been consistently shown to have a stronger negative influence on test performance than emotionality in all age groups and both sexes, and across diverse cultures ${ }^{27}$. This study made use of this to evaluate test anxiety.

Exams anxiety has been consistently reported to cause psychological disturbance for students, ${ }^{16,28,22}$. In a study by ${ }^{29}$ there was significant association of anxiety being characterized by examination dissatisfaction and being overburdened with test schedule with psychological distress among medical students. This was supported by $^{30}$ when they found out that vast syllabus and tests and exams are amongst one of the most common sources of stress for students in Nepal. Similarly, in the report by ${ }^{31}$ medical students in all four years had mean Hopkins Symptoms Check List (HSCL) anxiety subscale scores more than a standard deviation higher than the norms for the general population.

Likewise,there has been an establishment of relationships between psychological distresses or stressful life events and self-esteem as been reported by ${ }^{32}$ when they found out that there is a relatively high perceived 
stress, low acculturation, moderate self-esteem with no significant gender differences among a 472 Mexican American students aged 14-17 but further analysis suggests that self-esteem was the most predictive of all in protective overall coping strategy when confronted with negative life stressors. Also ${ }^{33}$ reported that a significant negative correlation between self-esteem and both academic and life stresses in a 675 undergraduates students suggesting that students with high self-esteem are less stressed than students with low-esteem. There was a contrary report $\mathrm{by}^{34}$, who found out that as the numbers of life events increased, the level of self-esteem decreased in a 2154 North Dakota students ages 14 and 19.Deconstructing Life Events Inventory for University Students (LEIU), the third factor, which is academic problems/events, students with high self-esteem is less stressful with students with low self-esteem ${ }^{35}$.

Longitudinal studies in the UK about nursing study and stress found unrelated results. For example, while ${ }^{36}$ found the majority of students commenced their nurse training with average levels of self-esteem as classified by the Tennessee Self Concept Scale, by the time they finished their education their self-esteem had fallen to the point that $95 \%$ of the students perceived themselves as anxious, depressed and unhappy, while ${ }^{37}$ found that students' self-esteem rose as they neared the end of their education programme, although their overall self-esteem levels at their highest were only average.

With this background, this study will be testing the hypothesesthat high scorers on psychological distress will experience less psychological distress than low scorers on psychological distress; low scorers on test anxiety will experience more psychological distress than high scorers on self-esteem and the third hypothesis states that age and gender will jointly and independently predict psychological distress.

\section{Methods}

This was a cross-sectional study that looked into the influence of exam sex, age, test anxiety and selfesteem on psychological distress.

\section{Setting}

The study was conducted at Federal Neuropsychiatric Hospital, Uselu, Benin City, Edo State, Nigeria on Masters Students in Clinical Psychology during their internship period. The students were from Nnamdi Azikwe University, Awka, Anambra State and Ambrose Alli University, Ekpoma, Edo State, all in Nigeria.

\section{Sample Size}

Out of 160 students, 147 participants were analyzable the reason being attrition. The participants were conveniently chosen for this study. Female were $84(57.1 .9 \%)$ while male were 63 (42.9\%). The mean age was 28.54 while SD was 5.124 .

\section{Procedure}

The questionnaires were administered on the students after due process of collecting ethical approval from the hospital and getting individual consent. Some of the students took some days to finish the questionnaires. They all displayed a degree of understanding about the questions and answered accordingly.

\section{Data Analysis}

The hypotheses were tested using t-test statistical data and multiple regression analysis. The descriptive statistics used involved frequencies, mean and standard deviation for socio-demographic variables.

\section{Research Instrument}

Test anxiety was measured using Test Anxiety Inventory, (TAI) by ${ }^{38}$. This questionnaire contains 20 items, and the subjects are instructed to respond according to how they generally feel by reporting the frequency with which they have experienced. The responses to the items of test anxiety questionnaire comprise the 4 point scales including (1) almost never; (2) sometimes; (3) often; (4) almost always ${ }^{38}$ provided the original psychometric properties for American Samples while ${ }^{39}$ provided the properties for Nigerian Samples Cronbach's Alpha as .56 while Reliability score was reported as .62.

Self-esteem was assessed through Index of Self-esteem. It is 25-item inventory designed to measure the selfevaluative and self-perceived component of self-concept which is the sum total of the self-perceived and the other -perceived views of the self held by a person. Thereliability coefficient was .93 while the validity score was .92. While psychological distress was measured through Symptoms Checklist-90 with reliability score ranging from .77 for psychoticism and .90 for depression, reliability score was ranged from .26 for Hostility to .47 for neuroticism. 


\section{Result}

Table 1shows that there is less psychological distress experienced by high scorers on the psychological distress measure, $t(145=-15.49, \mathrm{p}<.05)$. Therefore, the hypothesis is confirmed.

Table 1:Summary of t-test analysis showing difference between high self esteem and low self esteem on

\begin{tabular}{llcccccc}
\multicolumn{9}{c}{ psychological distress. } \\
\hline DV & $\begin{array}{l}\text { Source } \\
\text { of variance }\end{array}$ & $\mathbf{N}$ & $\overline{\boldsymbol{x}}$ & SD & df & T & P \\
\hline \multirow{2}{*}{ Psychological Distress } & High ISE & 86 & 23.01 & 11.65 & \multirow{2}{*}{-15.49} & $<0.05$ \\
& Low ISE & 61 & 65.98 & 21.70 & & & \\
\hline
\end{tabular}

Table 2:Summary of t-test analysis showing difference in high and low test anxiety on psychological distress

\begin{tabular}{|c|c|c|c|c|c|c|c|}
\hline DV & $\begin{array}{l}\text { Source } \\
\text { variance }\end{array}$ & of $\mathbf{N}$ & $\bar{x}$ & SD & df & $\mathbf{T}$ & $\mathbf{P}$ \\
\hline \multirow[b]{2}{*}{ Psychological Distress } & Low TAI & 97 & 25.47 & 12.97 & \multirow[b]{2}{*}{145} & \multirow[b]{2}{*}{-15.96} & \multirow[b]{2}{*}{$<0.05$} \\
\hline & High TAI & 50 & 70.66 & 21.27 & & & \\
\hline
\end{tabular}

In the table 1 and 2 above, it was shown that there is significant difference between low scorers on Test Anxiety Inventory and high scorers on test anxiety on psychological distress, $t(145=-15.96, p<.05)$ which confirms the stated hypothesis.

Table 3: Summary of multiple regression analysis of sex, age on psychological distress

\begin{tabular}{|c|c|c|c|c|c|c|c|}
\hline Model & B & $\mathbf{T}$ & $\mathbf{P}$ & $\mathbf{R}$ & $\mathbf{R}^{2}$ & $\mathbf{F}$ & $\mathbf{P}$ \\
\hline Sex & -0.00 & $\begin{array}{l}-0.004 \\
\end{array}$ & $>.05$ & & & & \\
\hline Age & -0.027 & -0.027 & $>.05$ & 0.021 & 0.001 & 3.00 & 3.05 \\
\hline
\end{tabular}

The table above reveals that there is no joint and independent prediction of sex and gender on psychological distress, $\left(\mathrm{F}=\mathrm{P}>.05, \mathrm{R}=.027, \mathrm{R}^{2}=.001\right)$. Therefore the hypothesis is rejected.

\section{Discussion}

Evidently from the result, there is less psychological distress experienced by high scorers on the self esteem measure, $\mathrm{t}(145=-15.49, \mathrm{p}<.05)$. This suggests that being fit psychologically in the university can be influenced by high self-esteem. This was supported by ${ }^{32}$ with the establishment that self-esteem was the most predictive of all factors considered in their study to be the most protective overall coping strategy when students were confronted with negative life stressors.

There is a significant relationship between low scorers on Test Anxiety Inventory and psychological distress as confirmed by the results. This result is in agreement with the evidence given by ${ }^{32}$, which confirmed that there was significant association of anxiety being characterized by examination dissatisfaction and being overburdened with test schedule with psychological distress among medical students. Sreeramareddy ${ }^{30}$ had similar results to submit claiming that vast syllabus and tests and exams are amongst one of the most common sources of stress for students in Nepal.

Genderand age failed to predict psychological distress as revealed by the results, but studies such as ${ }^{14,15}$ reported that psychological distress is higher among female than male students. This view is shared by is also shared by ${ }^{16,17}$ disagreed with the finding with the claim that 20 years or below were more significantly associated with level of psychological distress.

\section{Implications And Conclusion}

The study joins in sounding call to the relevant authorities especially school administrators, school psychologists/counselors and other helping professions in academic area to be more proactive in the monitoring and offering support for students in the academic/exam structure by making classes and other means of disseminating knowledge more enticing so that students will be at their best during exams as exams are still considered to be the most used medium of determining students' performance. Properly addressed, test and performance anxiety can be significantly reduced in the school setting.

Similarly, recognition and effective intervention should begin as regards psychological distress from school psychologists, clinical psychologists, and other mental health professionals so that they can help students overcome it. Mental health specialists and teachers should be strong advocates in helping students improve school performance and reduce the risk of the development of any psychological problems.

Factors such as environment, academic, familial, correlates of stress, drug history, and other sources of stress for university students can be considered in further study. 
It can be concluded that there was significant relationship between low scorers on Test Anxiety Inventory and psychological distress and also thatthere was significant relationship between low scorers on Test Anxiety Inventory and psychological distress, but that there was no joint and independent prediction of sex and gender on psychological distress.

\section{X1. Limitations}

The study is a cross-sectional study in which participants are considered here and now; this may not be accounting for changes that may come up at other times but which longitudinal study can take care of. The study though establish a relationship between the psychological factors, it was not enough to establish the causal effect of the variables.

\section{References}

[1] World Health Organization. Investing in Mental Health. Geneva 2003: WHO.

[2] Al-Naggar, R.A., \& Al-Naggar, D.H. Prevalence and Associated Factors of Emotional Disorder among Malaysian University Students. International Journal of Collaborative Research on Internal Medicine \& Public Health,2012 Vol.4, No 2.

[3] Adewuya A.O., Ola B.A., Aloba O.O., Mapayi B.M, \&Oginni O.O. Depression amongst Nigerian university students: prevalence and sociodemographic correlates. SocPsychiatrPsychiatrEpidemiol; 2006: 41:674-678.

[4] Tomoda A., Mori K., Kimura M., Takahashi T., \& Kitamura T. One year prevalence and incidence of depression among first year university students in Japan: A preliminary study. Psychiatry Clin. Neurosci;2000:54:583-8.

[5] Voelker R. Mounting student depression taxing campus mental health services. JAMA. 2003; 289:2055-2056.

[6] Andrews, B., \& Wilding, J. The relation of depression and anxiety to life-stress and achievement in students. British Journal of Psychology 95 (4),2004:509-521.Roy

[7] Royal College of Psychiatrists. The mental health of students in higher education. Council, Report CR112,2003:London.

[8] Dyrbye, L.N., Thomas, M.R., \&Shanafelt, T.D. Medical student distress: Causes, consequences, and proposed solutions. Mayo.Clin. Proc.2005:80(12): 1613-1622.

[9] Dyrbye, L.N., Thomas, M.R., \&Shanafelt, T.D. Systematic review of depression, anxiety, and other indicators of psychological distress among US and Canadian medical students. Acad. Med. 2006:81(4): 354-373.

[10] Yusoff, M.S.B., Abdulrahim, A.F. \&Yaacob, M.J. Prevalence and sources of stress among UniversitiSains Malaysia Medical Students. Malays. J. Med. Sci. 2010:17(1): 30-37.

[11] Yusoff, M.S.B., Liew, Y.Y., Ling, H.W., Tan, C.S., Loke, H.M., Lim, X.B. \&Abdulrahim, A.F. A study on stress, stressors and coping strategies among Malaysian medical students. International Journal of Students' Research 2011:1(2): 45-50.

[12] Farnsworth, D.L. Mental health and social change. Ann. Int. Med., 1973:73, 467-47

[13] Plunkett, S. W., Radmacher, K. A., Moll-Phanara, D. Adolescent life events, stress and coping: A comparison of communities and genders. Professional School Counseling, 2000:3(5), 356-367.

[14] Kaya B, Pehlivan E. Prevalence of depressive symptoms, ways of coping, and related factors among medical school and health services higher education students. Turk PsikiyatriDerg2007:18:137-46. Turkish

[15] Dahlin M, Joneborg N, \&Runeson, B. Stress and depression among medical students: A cross-sectional study. Med Educ.2005:39:594-604.

[16] Rahul, S. N., Jerry S. A., Donald S., \& Suzette P. Sources of Stress and Psychological Disturbance among Dental Students in the West Indies. Journal of Dental Education, 2002:Vol. 66, No. 9

[17] Tabassum A., Fatima A., Mussarat R.,\&Faiza A.K. Depression, Anxiety and Their Associated Factors among Medical Students. Journal of the College of Physicians and Surgeons Pakistan 2010, Vol. 20 (2): 122-126

[18] Paton, G. Exams culture 'fuelling teenage mental health problems'. The Telegraph 2010

[19] Cizek, G.J. \& Burg, S.S. (2006). Addressing Test Anxiety in a High-stakes Environment: Strategies for Classrooms and Schools. Thousand Oaks, California: Corwin Press.

[20] Wren, D.G. \& Benson, J. Measuring test anxiety in children: Scale development and internal construct validation. Anxiety, Stress, and Coping 2000:17(3), 227-240

[21] Pekrun, R. A social-cognitive, control-value theory of achievement emotions. In J. Heckhausen (ed.) Motivational Psychology of Human Development: Developing Motivation and Motivational Development, Advances in Psychology 2000:131, (pp. 143-163). Amsterdam: Elsevier.

[22] McDonald, A.S. The prevalence and effects of test anxiety in school children. Educational Psychology 2001:21(1), 89-101

[23] Hagtvet, K.A., Man, F. \& Sharma, S. Generalizability of self-related cognitions in test anxiety. Personality and Individual Differences2001: 31(7), 1147-1171

[24] Zeidner, M. \& Matthews, G. Test anxiety. In R. Fernández-Ballesteros (ed.) Encyclopedia of Psychological Assessment, 2003:Vol. 2 M-Z (pp. 964-969). London: SAGE Publications.

[25] Zeidner, M. Test anxiety in educational contexts: Concepts, findings, and future directions. In P.A. Schutz, \& R. Pekrun (Eds.). Emotion and Education 2007:(pp. 165-184). San Diego, CA

[26] Meijer, J. Learning potential and anxious tendency: Test anxiety as a bias factor in educational testing. Anxiety, Stress, and Coping, 2001:14(3), 337-362.

[27] Chung, G.K., O’Neil W.K., Delacruz, H.F., \&Bewley, W.L. The role of anxiety on novices' rifle marksmanship performance. Educational Assessment 2005:10(3), 257-275.

[28] Christopher, E.E, Koofreh, J.D, Uduak, P.A., \&Nyebuk, E.D. Academic stress and menstrual disorders among female undergraduates in Uyo, South Eastern Nigeria: The need for health education. Nigerian Journal of Physiological Science; 2011:26: 193-198

[29] Alvil T., Assad F., Ramzan M., \& Khan F.A. Depression, Anxiety and Their Associated Factors Medical Students. Journal of the College of Physicians and Surgeons Pakistan, 2010:Vol. 20 (2): 122-126.

[30] Sreeramareddy C.T, Shankar P.R, Binu V.S, Mukhopadhyay C, Ray B, \&Menezes R.G. Psychological morbidity, sources of stress and coping strategies among undergraduate medical students of Nepal. BMC Med Educ2007; 7:26-31.

[31] Lloyd, C., \&Gartrell N.K. Psychiatric symptoms in medical students. Compr Psychiatry. 1984;25:552-65.

[32] Guinn, B., \& Vincent, V. Determinants of coping responses among Mexican American adolescents. Journal of School Health,2001:72(4), 152-156. 
[33] Abouserie, R. Sources and levels of stress in relation to locus of control and self-esteem in university students. Educational Psychology, 1994:14(3), 323-329.

[34] Youngs Jr., G.A., \&Rathge, R. Adolescent stress and self-esteem. Adolescence, 1990; 25(98), $333-339$.

[35] Emil, S. (2003).Self-Esteem and Stressful Life Events of University Students. (Unpublished Masters' Thesis). Submitted to Graduate School of Social Sciences of Middle East Technical University.

[36] Randle, J. Changes in self-esteem during a 3 year pre-registration diploma in higher education (nursing) programme. Learning in Health and Social Care2003:2 (1), 51-60.

[37] Begley, C., \&Glacken, M. Irish nursing students' changing levels of assertiveness during their pre-registration programme. Nurse Education Today 2004:24 (7), 501-510.

[38] Spielberger, C. D. Preliminary Professional Manual for the test anxiety inventory. Palo Alto, CA: 1980:Consulting Psychologists Press.

[39] Omoluabi, P.F. Validation of test anxiety inventory for Nigerian samples. Nigerian Journal of Basic and Applied Psychology, 1993:3 (1), 31-47. 